\title{
RANCHEIROS DO RIO MOGI-GUAÇU, MUNICÍPIO DE BARRINHA-SP: UMA EXPERIÊNCIA DO NOVO RURAL BRASILEIRO
}

FIGUEIREDO, Rosane Teresinha Petroróssi de. Mestrado em Desenvolvimento Regional e Meio Ambiente do Centro Universitário de Araraquara - Uniara. E-mail: mestrado@uniara.com.br.

LORENZO, Helena Carvalho De. Pesquisadora e docente do Programa de Mestrado em Desenvolvimento Regional e Meio Ambiente do Centro Universitário de Araraquara - Uniara. E-mail: hclorenzo@uniara.com.br.

\section{RESUMO}

O presente artigo busca contribuir com os estudos sobre os desafios para o desenvolvimento de pequenas comunidades rurais que procuram conciliar o desenvolvimento de atividades agrícolas e não agrícolas como um importante instrumento de combate à pobreza rural, à instabilidade da renda agrícola e ao êxodo rural. A pesquisa foi realizada com rancheiros instalados às margens do rio Mogi-Guaçu, no município de Barrinha-SP, que tem como característica peculiar ser cidade-dormitório de boias-frias que trabalham nas usinas de canade-açúcar da região de Ribeirão Preto-SP. A comunidade estudada está formada por ranchos, locais de moradias e unidades de produção, onde se realizam diversas atividades econômicas agrícolas e não agrícolas que interagem entre si e com associações locais. As referências teóricas estão fundamentadas em autores que discutem as condições de formação do "novo rural brasileiro" e da "pluriatividade no campo" e explicam o tema a partir de um paradoxo entre a presença de grandes latifúndios e da monocultura e, de outro, das pequenas propriedades familiares que desenvolvem estas atividades para permanecerem no campo. Constatou-se uma experiência que não se enquadra somente nos estudos sobre a pluriatividade no campo; a importância da cooperação entre os rancheiros com forma de garantia de sustentação de suas atividades; e a importância da atuação do setor público como garantia de apoio institucional. Assim, no âmbito dos estudos sobre o novo rural, o estudo de caso apresenta uma experiência inovadora praticada por atores que criaram uma forma de organização ímpar para gerar trabalho e renda.

Palavras-chave: Pluriatividade; Comunidades rurais; Inclusão territorial.

\begin{abstract}
This article aims to contribute to studies on the challenges for the development of small rural communities that seek to reconcile the development of agricultural and non agricultural activities as an important instrument to combat rural poverty, the instability of farm incomes and rural depopulation. The survey was conducted with ranchers installed on the Mogi Guaçu river, located in the town of Barrinha, SP, which has as a peculiar characteristic to be a dormitory town of day laborers who work in sugar cane plantations in the region of Ribeirão Preto / SP. The community is made up of ranches, housing and local production units, where various economic activities agricultural and non agricultural ones- take place and interact among themselves and with local associations. The theoretical references are based on authors who discuss conditions of formation of the "new Brazilian rural" and "multi-activity in the field", explaining the issue from a paradox between the presence of large estates and monoculture, on one hand, and, on the other hand, of small family farms that develop these activities to remain in the field. The research has showed an experience that does not fit only on studies of pluriactivity in the field but showed the importance of cooperation between ranchers as a form of guarantee of support for their activities and the importance of the role of the public sector as a guarantee of institutional support. In the context of studies of the new countryside, the case study presents an innovative experience practiced by actors who have created a unique form of organization to generate employment and income.
\end{abstract}


KEYwORDs: Pluriactivity; Rural communities; Territorial inclusion.

\section{INTRODUÇÃo}

As transformações vivenciadas pelo campo a partir do desenvolvimento tecnológico das últimas décadas têm revelado experiências bastante diversificadas, contribuindo para alterar as concepções que tratavam de forma antagônica o rural e o urbano.

Por um lado, o processo de desenvolvimento via industrialização do campo tem eliminado gradativamente a separação rígida e tradicional entre rural e urbano, unificando-os em uma unidade dialética. Por outro, as experiências de desenvolvimento de pequenas comunidades rurais vêm rompendo com o discurso conservador que até então persistia, de que o "rural" é subserviente ao "urbano". Algumas experiências recentes apontam um novo rural com mais autonomia em relação às cidades e regiões próximas, dando lugar a um novo rural.

Essas transformações que o mundo rural brasileiro atualmente vivencia vêm sendo estudadas por diversos autores, permitindo uma nova definição do que seja "rural" e de sua delimitação territorial. Alguns autores que vêm estudando esse moderno desenvolvimento rural mostram que hoje há uma nova realidade no meio rural, em praticamente todos os países: há uma grande diversidade de ocupações, serviços e atividades produtivas, novas funções não exclusivamente produtivas, como residências, esportes, lazer, maior interação como entorno urbano e uma revalorização do rural propiciada pelo turismo, artesanato, dentre outras, que podem inverter o movimento de uma fração da população em direção às áreas rurais (KAGEYAMA, 2008; WANDERLEY, 2000; GOMÉZ, 2001).

Para Schneider (2000), um dos autores que estudam esses processos no Brasil, as transformações das formas de ocupação da força de trabalho no meio rural estão trazendo consigo uma complexidade de alterações sociais e de identificação cultural que vão muito além das mudanças perceptíveis na performance dos mercados de trabalho. Essas alterações ou mudanças implicam as formas de funcionamento das unidades familiares, levando ao aparecimento de novas estratégias individuais e coletivas que objetivam garantir a reprodução dos grupos e das comunidades rurais.

$\mathrm{O}$ presente artigo, buscando contribuir com os estudos sobre os novos desafios para o desenvolvimento de pequenas comunidades rurais, descreve e analisa as práticas econômicas de autogestão que vêm sendo realizadas, desde o final da década de 1990, pela população ribeirinha do rio Mogi-Guaçu, localizada no município de Barrinha, Estado de São Paulo, que tem como característica peculiar ser cidade-dormitório de trabalhadores das usinas de cana-de-açúcar da região de Ribeirão Preto.

A base da economia do município da Barrinha é a agricultura da cana-de-açúcar, alguma pecuária, silvicultura e exploração florestal. Barrinha não tem usinas e tem poucas indústrias. A maioria da sua população trabalha no corte de cana-de-açúcar e não há muitas opções de emprego em outras atividades. Diante desse fato, o município passou a ser conhecido como cidade-dormitório, pois os trabalhadores rurais permanecem na maior parte do dia nas lavouras de cana-de-açúcar da região de Ribeirão Preto e retornam para o município somente ao anoitecer.

Segundo Silva (2008), Barrinha vive o lado "B" do agronegócio, com trabalhadores desempregados, sendo que a maioria dos empregados apresenta baixa qualificação. Amecanização aliada à falta de qualificação dos trabalhadores rurais têm sido as grandes vilãs. Uma colheitadeira substitui o trabalho de 120 cortadores de cana. Semusinas na cidade, sem qualificação profissional e com pouca atuação da prefeitura, muitas famílias têmse voltado ao espaço ribeirinho, onde fica mais fácil sobreviver. A mecanização acelerada do setor sucroalcooleiro tem descartado o cortador de cana desse município e dos municípios vizinhos. O setor exige uma alta produtividade que apenas o trabalhador mais jovem consegue cumprir. O setor busca migrantes que são jovens e, com isso, fica livre da responsabilidade social, dado que estes trabalhadores permanecem no local por quatro meses e depois vão embora. As usinas e o poder público não têm responsabilidades formais, e não apresentam nenhuma alternativa ou opção de 
trabalho ou moradia a esses trabalhadores.

Esse quadro de desemprego, aliado aos altos preços dos aluguéis de imóveis na cidade - agravado pela especulação imobiliária que elevou os preços dos terrenos urbanos no município -, fez com que muitas familias rurais e mesmo familias urbanas migrassempara áreas rurais à procura de novas atividades e moradias, formando verdadeiras comunidades, algumas bastante organizadas.

Este artigo apresenta o estudo realizado em uma dessas comunidades ribeirinhas. Aponta os erros e acertos em sua trajetória, analisa as relações que explicam sua sobrevivência e acomodações, e sugere espaços de atuação e subsídios para proposições de políticas públicas locais de apoio ao emprego e moradia para essas populações.

Com esses propósitos mais gerais, o objetivo do presente estudo foi analisar uma dessas comunidades ribeirinhas para conhecer as condições que explicam o seu surgimento, sobrevivência e continuidade enquanto grupo. Procurou-se analisar as relações, as formas e arranjos que essa população criou e recriou para garantir sua sobrevivência e continuidade.

O presente artigo está organizado em cinco itens, além desta introdução, em que estão explicitados os objetivos de pesquisa. No segundo item busca-se apresentar os fundamentos teóricos da análise, elaborados a partir de considerações sobre: a) a contribuição dos estudos já realizados sobre o tema, que revelam a natureza e o significado do desenvolvimento de novas atividades econômicas e sociais no mundo rural; b) a definição legal do que seja rural, aspecto que se revelou importante para este estudo, na medida em que a questão legal é fator que impede a regularização dos lotes e das atividades que se desenvolvem no local. No terceiro item foi explicitada a metodologia utilizada na pesquisa e também foi caracterizado o universo estudado. No quarto item estão apresentados os resultados da pesquisa. Como se verá, o resultado da investigação mostrou a importância da cooperação entre os rancheiros como forma de garantia de sustentação de suas atividades, e também a importância da atuação do setor público e de políticas públicas como garantia de apoio institucional.

\section{Desenvolvimento rural no Brasil: novas PERSPECTIVAS DE ESTUDO}

O tema do desenvolvimento rural no Brasil vem crescendo nas três últimas décadas. Até recentemente o debate girava principalmente em torno da economia agrícola, do agronegócio e de seus mercados. Diversos fatores, aqui apenas mencionados, contribuíram para uma nova perspectiva nos estudo sobre o rural identificando novas realidades que têm possibilitado a elaboração de novos conceitos e novas categorias de análise. Em primeiro lugar, cabe destacar a influência da evolução do conceito de desenvolvimento, surgido no corpo teórico da economia e da sociologia, principalmente, visto como um processo que envolve não apenas o crescimento econômico, como também múltiplas dimensões, como sociocultural, políticoinstitucional e ambiental. Em segundo, a própria evolução do conceito de rural que, de um espaço quase exclusivamente agrícola, adquiriu contornos de um tecido econômico e social diversificado e valorizado, comprovado a partir das várias experiências mundiais bem-sucedidas de desenvolvimento territorial.

Os estudos aqui apresentados, considerados pelos pesquisadores envolvidos nesta pesquisa como relevantes para compreensão do tema, estão relacionados às condições que explicamo surgimento de novas experiências no rural brasileiro e suas dificuldades de sobrevivência e reprodução das experiências. Nessa direção se destacam Schneider (2007), Veiga (2001), Silva (1999), Shiki, Silva e Ortega (1997), dentre outros.

O debate sobre o desenvolvimento rural no Brasil ganhou força a partir da década de 1990 em função, sobretudo, do interesse do Estado e das políticas públicas e da realização de vários estudos que contribuíram para reorientar as pesquisas sobre desenvolvimento rural (SCHNEIDER, 2007). Dentre esses estudos se destacam, em primeiro lugar, os que ressaltam o fortalecimento das discussões em torno da agricultura familiar e, principalmente, sobre seu 
crescimento como categoria política ligada à recomposição do movimento sindical de trabalhadores rurais. Outros estudos apontam a expansão do Programa Nacional de Fortalecimento da Agricultura Familiar-Pronaf, que resultou na crescente importância da influência do Estado e de políticas públicas próativas para o financiamento de pequenos empreendimentos agrícolas. Ainda se destacam os estudos que ressaltam as mudanças de posição das elites em relação às políticas sociais compensatórias para o meio rural. Finalmente o resgate dos temas da sustentabilidade ambiental, que também contribuiu para ampliar o debate sobre o desenvolvimento rural.

Também os dados apontados por Veiga (2001) mostram a importância da população rural no Brasil e destacam que se tinha uma visão pouco realista do grau de urbanização, dado que, segundo os dados elaborados pelo autor, na realidade, apenas $60 \%$ da população brasileira pode ser considerada urbana. Veiga (2001), analisando o desenvolvimento rural em termos de projetos alternativos para o campo brasileiro, e em oposição aos projetos voltados ao agrobusiness, destaca algumas novas características do desenvolvimento rural que apontam para o aumento da presença das economias locais, da diversidade multisetorial, da agricultura em sistema de policultura, da salubridade do meio ambiente e da pluriatividade das famílias rurais para absorção de mão de obra. Há, assim, um novo ambiente rural em formação que precisa ser analisado e compreendido, tanto em suas realidades, quanto na diversidade de suas relações.

Uma importante questão para a compreensão do tema aqui analisado foi a perspectiva de estudo conhecida como Projeto Rurbano, com ênfase nas atividades agrícolas e não agrícolas. A urbanização avançou nas áreas rurais, a partir do processo capitalista de modernização tecnológica que se expandiu no meio rural, modificou a estrutura e a organização da produção, produzindo muitos problemas e novas relações, instalando-se neste setor uma nova dinâmica, marcada por atividades agrícolas e não agrícolas. Nos termos de Silva (1999), estamos diante de um "novo" rural. Para Corrêa, Corrêa e Gerardi (2001), nas últimas décadas ocorreram significativas alterações no conteúdo socioespacial de muitas comunidades, anteriormente localizadas fora do perímetro urbano e, por isso, identificadas como áreas rurais.

Pode-se dizer que o rural hoje, só pode ser entendido como um "continuum" do urbano do ponto de vista espacial e do ponto de vista da organização da atividade econômica; as cidades não podem mais ser identificadas apenas com a atividade industrial, nem os campos com agricultura e a pecuária. Menéndez (apud SHIKI; SILVA; ORTEGA, 1997, p.76) ressalta que o rural ainda hoje é definido usualmente como o mundo não-urbano ou não-metropolitano. E que a visão que se tem do mundo rural ainda está completamente vinculada à evolução do mundo agrário, enquanto a indústria e os serviços parecem ser características "naturais" do meio urbano. Mostra, nessa direção, que desde o final de século XX as áreas rurais dos países desenvolvidos começaram exibir formas sociais e econômicas de organização paradigmáticas à medida que a sociedade saiu dos "padrões fordistas". Dentro desse raciocínio, ressalta: a) a mudança rural é multidimensional, ou seja, não pode ser vista apenas da ótica econômica ou social, nem do ponto de vista estrito da produção e/ou do consumo; b) é preciso incorporar a esfera da circulação como parte das "novas formas", mais especificamente, o capital financeiro; c) o significado do atual processo de "commodotization" é que as áreas rurais estão crescentemente associadas com atividades orientadas para o consumo, como lazer, turismo, residência, preservação do meio ambiente, etc.

Apesar dessas mudanças, as políticas rurais continuam a ser direcionadas basicamente para reduzir o isolamento das populações locais, ou seja, melhoria nos transportes, na comunicação e nas suas condições de vida (habitação e saúde). Ainda não se tem levado em conta as mudanças ocorridas nas zonas rurais, e que essas populações têm novas necessidades típicas de uma sociedade pós-industrial, como, por exemplo, a de estabelecer um zoneamento para definir áreas industriais e de moradia, áreas de preservação ambiental, etc. 
Para Shiki, Silva e Ortega (1997), o novo rural brasileiro combina atividades agropecuárias com outras atividades não agrícolas, como as novas atividades que vêm-se desenvolvendo, como lazer, turismo, conservação da natureza, moradia e prestação de serviços pessoais. Segundo o autor, a pluriatividade no mundo rural hoje se configura de quatro formas básicas: a) através de um mercado de trabalho relativamente indiferenciado, que combina desde a prestação de serviços manuais atéo emprego temporário nas indústrias convencionais; b) através das combinações de atividades tipicamente urbanas do setor terciário com o "management" das atividades agropecuárias; c) pela presença de unidades familiares que se individualizaram no que diz respeito à gestão produtiva, liberando os membros da família para buscarem fora outras atividades; d) pela presença de pequenos proprietários rurais que reduziram o tempo dedicado às atividades agropecuárias em busca de outras atividades rurais, que lhes proporcionam maior renda.

Ainda em relação à pluriatividade no campo, conforme Shiki, Silva e Ortega (1997), podem ser citadas outras atividades não agrícolas que têm chamado atenção nas últimas décadas nos espaços rurais, que é a proliferação dos sítios de recreio ou chácaras, como são conhecidas no interior do Estado de São Paulo. Essas chácaras de recreio apresentam atividades produtivas de valor comercial considerável; muitas vezes as atividades econômicas articuladas nesses espaços acabam sendo responsáveis pelas despesas das mesmas; muitas se dedicam a criação de peixes, abelhas, aves e outros pequenos animais; também se pode encontrar produção de flores e plantas ornamentais, frutas e hortaliças, atividades de recreação e turismo (pesque-pague, hotel fazenda, pousadas, restaurantes, spas).

É importante enfatizar que a proliferação das chácaras de recreio, esporte e lazer têm como aspecto positivo a resistência da preservação da paisagem rural. Também, de certa forma, essas chácaras expulsam e/ ou impedem das proximidades do perímetro urbano, as grandes culturas agrícolas que, em geral, utilizam grandes quantidades de insumos químicos e máquinas pesadas e dão novo uso às terras. Outro aspecto positivo que também merece ser mencionado é o da geração de emprego e renda e a possibilidade de capacitação e recolocação de trabalhadores para essas atividades, colaborando para a amenização do desemprego no local. E é fundamental que se entenda que, além do arroz, feijão, carne, boias-frias e fazendeiros, o mundo rural criou outro tipo de riqueza, uma riqueza cultural, que abarca bens e serviços não materiais e podem ser desenraizados, se não forem preservados. Assim, por vezes, a resistência por parte dos atores sociais envolvidos em manter a cultura do local, em espaços de cultura e lazer, oferece acima de tudo a possibilidade de, no espaço local-regional, combinar postos de trabalho com atividades de recreação e preservação dos costumes locais.

Em suma, em todos os autores analisados, já não se pode caracterizar o meio rural brasileiro como somente agrário. Os empregos rurais não podem mais ser explicados apenas a partir do calendário agrícola, pois há um conjunto de atividades não agrícolas que respondem cada vez mais pela nova dinâmica populacional do meio rural brasileiro.

\section{Novos espaços e o surgimento de pequenas LOCALIDADES RURAIS}

As mudanças atualmente em curso no meio rural brasileiro, devido à incorporação de atividades tipicamente urbanas, têm gerado transformações nas formas de ocupação da força de trabalho e estão trazendo consigo uma complexidade de alterações sociais e culturais que, na realidade, vão muito além das mudanças perceptíveis no desempenho do mercado de trabalho. Essas alterações ou mudanças implicam as formas de funcionamento das unidades familiares, levando ao aparecimento de novas estratégias individuais e coletivas que objetivam garantir a reprodução dos grupos e das comunidades rurais (SCHNEIDER, 2003).

A emergência da pluriatividade no campo não significa que as famílias domiciliadas nos espaços rurais estejam abandonando as atividades agrícolas; pelo contrário, a pluriatividade resulta da interação entre as decisões individuais e coletivas com o contexto social 
e econômico em que estas estão inseridas. São estratégias dos indivíduos e das comunidades rurais em driblar a crise econômica na qual estão inseridos; são formas alternativas e criativas de produção e trabalho, sejam agrícolas ou não agrícolas, específicas de cada localidade, cuja finalidade maior é, antes de tudo, a permanência da comunidade no mundo rural (SCHNEIDER, 2003).

Com relação às estratégias para localização de atividades familiares, Campanholae Silva (1999) apontam que uma divisão clara entre rural e urbano deixou de ser tão importante, pois as relações de troca se diversificaram e o enfoque passou a ser nos espaços ou territórios que dão suporte físico aos fluxos econômicos e sociais, relegando a um plano inferior a preocupação com seus limites geográficos. Com a crise de emprego nas áreas urbanas, que se acentuou desde a década de 1980, houve uma maior procura pelo meio rural, não somente para moradia, mas para desempenhar atividades, tais como prestação de serviços para autoconsumo ou trabalho por conta própria, empregados em agroindústrias, serviços públicos, mão de obra temporária na agricultura. Também outras atividades, como resorts ou acampamentos rurais, em decorrência do turismo rural, vêm atraindo pessoas para o lazer nas áreas rurais, assim criando outros empregos, como cozinheiras, jardineiros e camareiras em hotéis ou fazendas rurais.

Essas novas atividades têm-se revelado fonte de renda complementar para muitas famílias rurais que dependiam exclusivamente da agricultura, contribuindo para a fixação de populações em áreas ou regiões que possam oferecer melhores oportunidades e condições de vida. Assim, o meio rural não pode ser mais considerado como espaço exclusivo de atividades agrícolas, mas também de atividades não agrícolas que atingiram o mundo rural. Essas mudanças na concepção do que seja o rural somente começaram a emergir por meio da democratização dos espaços rurais, que ocorreu via articulação dos atores sociais que residem nessas localidades (CAMPANHOLA; SILVA, 1999).

Uma das alternativas para superar essa dicotomia tradicional, seja rural/urbano, seja a agrícola/não agrícola, é a adoção dos princípios da economia local/ regional, que considera as várias formas de integração e troca que se desenvolvem entre os segmentos espaciais e os setores de atividades. Campanhola e Silva (1999), por exemplo, consideram que o exemplo da Itália pode ser esclarecedor para a compreensão das mudanças espaciais da dicotomia entre urbano/ rural. Ressaltam, por esta razão, o local como território representativo de agrupamento das relações sociais. Também é o lugar onde a cultura e outros caracteres não-transferíveis têm sido sedimentados. É onde os homens estabelecem relações sociais, econômicas, culturais e ambientais e onde as instituições públicas e locais atuam para regular a sociedade. Representa, assim, lugar de encontro das relações de mercado e formas de regulação social que, por sua vez, determinam formas diferentes de organização da produção e diferentes capacidades inovadoras, tanto para produtos com base no custo relativo dos fatores, quanto para novas formas mais participativas de organização e gestão dessas atividades, destacando a importância de atores sociais diversos. As formas como os territórios italianos se desenvolveram a partir da década de 1970 mostram a importância das forças internas da sociedade. O território pode constituir-se como um todo, com várias dimensões, tais como ecológicas, culturais, sociais, econômicas, institucionais e políticas, sendo que as ações, a seu favor, devem integrar todas essas dimensões.

Um aspecto importante, sugerido por Campanhola e Silva (1999), refere-se às novas forças motoras que estão valorizando e dinamizando os espaços locais, particularmente os espaços rurais. São os incentivos de políticas públicas direcionadas, que ocorreram tanto nos países desenvolvidos como naqueles em desenvolvimento. O ponto central dessa análise está relacionado com o processo de descentralização/ municipalização. De acordo com os mesmos autores, os governos municipais parecem começar a interessarse pela gestão desses espaços, que têm sido vistos, cada vez mais, como parte da política social. Isso não apenas porque as dinâmicas locais, e, portanto, particulares, podem afetar outras de caráter mais universais, mas 
também porque o próprio processo de desenvolvimento parece estar dando lugar ao desenvolvimento de uma nova estrutura de oportunidades para a redefinição do papel dos governos e sociedades municipais, face ao novo rumo dos processos de desenvolvimento econômicos, político e social.

Além disso, de acordo ainda com os autores mencionados, os governos locais têm apresentado preocupações crescentes com a gestão dos recursos naturais; portanto, os espaços rurais ganharamuma maior atenção devido a sua representatividade, no momento em que evidenciam os recursos naturais de um país.

Em relação à descentralização dos espaços rurais, pode-se perceber que, a partir da Constituição de 1988, com a reforma na política fiscal no Brasil e coma instituição do Fundo de Participação dos Municípios FPM, por meio da transferência para os municípios de políticas e recursos que eram coordenados pelos governos estaduais e federais, a descentralização dos espaços rurais passou a ser percebida como local de atuação de políticas municipais e como ferramenta fundamental para redução da pobreza. Alguns autores apontam esse caminho para desmantelar a economias centralizadoras, uma forma de promover a democracia nesses espaços rurais.

Conforme Campanhola e Silva (1999), a descentralização dos espaços rurais passa pela participação dos atores sociais, pelo processo de associativismo de grupos diversos, aumento da credibilidade, ampliação do escopo dos projetos de desenvolvimento para além da agricultura, que incluam novas atividades não inerentes ao mundo rural, mas que possam ser prontamente realizados com redução das desigualdades sociais regionais.

Para os autores acima citados, por meio de um diagnóstico participativo podem ser identificados os problemas que afligem as comunidades e ou localidades rurais. Após o diagnóstico é possível propor uma política de desenvolvimento para o município e sua área rural, em que seja evidenciada a qualidade de vida, as melhores práticas para geração de renda dos agricultores rurais, o acesso a novas tecnologias e alternativas de produção, que não somente garantam a qualidade dos produtos como também se voltem para a conservação do meio ambiente, as melhores condições para a formação profissional dos agricultores, para a qualidade da educação nos espaços rurais, para valorização do conhecimento empírico da população local e rural e, acima de tudo, para que essa população tenha participação efetiva nas decisões que envolvam as políticas para o município.

Assim, conclui-se que atualmente os espaços rurais não são rigidamente mais articulados somente por atividades agrícolas: pode-se perceber outras atividades não agrícolas que já fazem parte da renda familiar complementar de muitos pequenos proprietários rurais. Muitos agricultores familiares já não dedicam todo seu tempo exclusivamente para sua própria produção, em decorrência das características sazonais das atividades agropecuárias. Todavia, apesar das transformações em curso, não se pode fazer uma leitura ingênua sobre o processo de democratização dos espaços rurais, pois na prática se percebem muitas dificuldades originárias de uma cultura autoritária, clientelista e pouco participativa.

Identifica-se, pois, uma situação bastante complexa sobre a natureza e potencialidades de desenvolvimento de pequenas localidades rurais. Todavia, para que seja possível criar condições para que se apreenda o processo de mudança que o mundo rural brasileiro atualmente vivencia, e estudar as características específicas do caso a ser apresentado, torna-se necessário também entender os aspectos legais do que seja o "rural".

\section{O ASPECTO LEGAL NA DEFINIÇão DO RURAL}

Existem claras dificuldades para se delimitar o que seja rural e o que seja urbano, do ponto de vista legal. No entanto, a realidade vem superando as diferenças e o assunto vem-se impondo pela sua própria importância real. Os estudos das diferenças conceituais entre o rural e o urbano estão tornando-se cada vez mais relevantes, sendo também importante o conhecimento das condições legais que permitem a consolidação e aprofundamento dessas experiências de resistência pela permanência no campo.

$\mathrm{O}$ aspecto legalé fundamental para a compreensão 
do tema, porque a definição e a delimitação legal dos espaços territoriais nas proximidades do perímetro urbano têm sido um problema constante, uma vez que há leis contraditórias e, por vezes, pouco esclarecedoras. Segundo Corrêa, Corrêa e Gerardi (2001), como as Constituições Federais não definiram o que seja rural e urbano, as leis ordinárias, como o Estatuto da Terra e outras que lhes sucederam, vêm contemplando focos diferentes: ora o princípio da destinação, ora o da localização. Para alguns, o critério diferencial centravase na destinação. Se o imóvel for usado para moradia, comércio ou indústria pode ser considerado urbano. Se explorado com agricultura ou pecuária, pertence à área rural, sendo, às vezes, também chamado rústico. Para outros, a diferença pode ser definida pela localização, ou seja, sobre as atividades realizadas em área urbana, ou as que estiverem situadas dentro do perímetro urbano, incide o Imposto sobre Propriedade Predial e Territorial Urbana - IPTU. Podem ser considerados rurais os imóveis que estiverem localizados fora do perímetro urbano, ou seja, nestes incide Imposto Territorial Rural - ITR.

Também a Constituição Federal de 1988 foi um instrumento de regulação da área rural, prevendo imunidade fiscal ao pequeno proprietário rural, e uma lei ordinária estabeleceu a imunidade, criando algumas isenções. Ao tratar sobre impostos da União, a Constituição Federal de 1988 estabeleceu, no artigo 153, que compete à União instituir imposto sobre a propriedade territorial rural, desestimulando a manutenção de propriedades improdutivas ao determinar que pequenas glebas rurais, definidas em lei, serão imunes se estiverem sendo exploradas, só ou com a família, desde que o proprietário não seja detentor de outro imóvel.

Para o caso analisado, um grave aspecto que pesa sobre o rural, principalmente com relação aos pequenos proprietários, se refere às consequências legais da crescente urbanização avançando sobre a área rural. Pode haver casos em que as políticas municipais podem estar impondo uma dupla tributação à população residente no campo. Esta situação enfraquece o direito de propriedade da área rural, as pequenas propriedades nessas áreas limítrofes ficam sem a proteção do Estado, proteção indispensável para consecução dos direitos e deveres sociais, individuais e coletivos estabelecidos pela própria Constituição.

No caso analisado, a compreensão dos aspectos legais a respeito da propriedade rural foram importantes, emrazão das dificuldades observadas para a regularização dos lotes e definição das condições de desenvolvimento dessas atividades alternativas no mundo rural.

\section{Metodologia da Pesquisa}

A pesquisa realizada teve como foco o estudo de uma comunidade ribeirinha do rio Mogi-Guaçu, localizada no município de Barrinha, Estado de São Paulo, constituída por 62 habitações denominadas de ranchos pela população, onde se desenvolvem atividades econômicas voltadas para um mercado consumidor no local e nas proximidades. Também fizeram parte do grupo analisado proprietários de 10 ranchos, selecionados para estudo aprofundado, diretores das associações relacionadas ao grupo, funcionários da prefeitura que cuidam da comercialização dos produtos da comunidade.

A razão da escolha do estudo das atividades desenvolvidas por este pequeno grupo se deveu não apenas à importância dessas atividades para a subsistência do mesmo, mas também por seu significado para a produção e reprodução econômica, social e cultural, sugerindo o desenvolvimento de um processo mais integrado de vida comunitária, no qual se observou, desde o início da pesquisa, um conjunto de atividades rurais e urbanas, mediadas pela presença de traços culturais, típicos da região. Assim, a pesquisa não se restringiu à questão da subsistência, mas focou as atividades econômicas agrícolas e não agrícolas e atividades culturais, que extrapolam a questão da subsistência e vêm garantindo uma melhor qualidade de vida para essa população. Todos os 62 ranchos estão voltados à própria subsistência, sendo que alguns produzem em pequena escala e vendem o excedente. Nem todos os produtores têm mercado consumidor definido. Em todos os ranchos foi possível encontrar algum tipo de agricultura, horticultura ou criação de pequenos animais para a subsistência das famílias. Há também ranchos que arrendaram suas respectivas terras 
para as usinas de cana-de-açúcar da região. Mas esse problema não foi abordado pela presente pesquisa.

A pesquisa teve como ponto de partida a caracterização do município e da região onde se localiza o agrupamento estudado. As variáveis selecionadas para o estudo realizado originaram-se da literatura sobre o tema, com vistas a identificar presença de atividades rurais e urbanos, entender as relações entre esses aspectos e contribuir para a compreensão dessas relações. O estudo envolveu aidentificação dos seguintes blocos de questões: a) atividades produtivas agrícolas e não agrícolas e condições de produção e de comercialização; b) emprego e renda e meio ambiente; c) existência e atuação de rede social, a articulação dos atores sociais e formação de associações; d) origem social dos rancheiros, preservação de traços culturais do mundo rural e outros elementos de "ruralidade" presentes no cotidiano; e) participação do poder público municipal.

Do ponto de vista metodológico e com a finalidade de encontrar evidência empírica que possibilitasse atingir os objetivos propostos, o trabalho foi organizado como um estudo de caso exploratório, com coleta de dados quantitativos e qualitativos. Foram utilizados dados secundários para a caracterização do município e da região, obtidos junto às instituições de pesquisa, como IBGE e Fundação Seade. O estudo de campo foi conduzido por meio da técnica de estudo de grupo focal. A técnica é utilizada para reunir informações de um grupo de pessoas que, sob a orientação do pesquisador, são estimuladas a prestar informações e discutir suas opiniões sobre um fato ou um caso.

\section{A ocupação ribeirinha do rio Mogi-Guaçu no MUNICÍPIO DE BARRINHA-SP}

O município de Barrinha, segundo dados do IBGE (2007), tem uma população de 25.642 habitantes. Apresenta taxa de urbanização elevada, acima da média de urbanização para o Estado de São Paulo, mas destaca-se que, a partir de 2001, em razão da Lei Orgânica do Município n. ${ }^{\circ} 1663$, de 25 de junho de 2001, que estendeu o perímetro urbano para as proximidades das margens do rio Mogi-Guaçu, a população urbana se ampliou com o aumento do espaço urbano. O IDH do município é 0,766 , bastante baixo, estando no nível médio - dados do Programa das Nações Unidas para o Desenvolvimento - PNUD (2000). Os municípios limítrofes são Dumont, Jaboticabal, Pradópolis, Ribeirão Preto e Sertãozinho.

A partir da lei orgânica municipal mencionada, a área rural do município de Barrinha, localizada às margens do rio Mogi-Guaçu, começou a ser intensamente ocupada por meio da construção de habitações para moradias, denominadas ranchos pela população local. Lotes de aproximadamente 10 hectares, localizados nas proximidades do rio Mogi-Guaçu, foram fragmentados em lotes de 1 hectare e de menos de $1 / 2$ hectare, vendidos a preços comparativamente mais baixos emrelação aos das cidades. Assim, a população ribeirinha no município cresceu substancialmente durante a última década, tanto pelos loteamentos regulares quanto por meio da ocupação por loteamentos clandestinos, cujas construções são realizadas dentro de uma área de preservação permanente, situada às margens do rio Mogi-Guaçu. Nessas áreas não há nenhuma fiscalização por parte do poder público municipal.

Apesar de a área dos ranchos se ter ampliado apenas mais recentemente, essa forma de ocupação das margens do rio Mogi-Guaçué bastante antiga e começou a ocorrer na década de 1930. O espaço às margens do rio foi sendo fragmentado em pequenas áreas, caracterizadas como sítios ou pequenas chácaras e, com o decorrer do tempo, essas áreas foram sendo divididas e subdivididas em pequenos lotes, vendidos por meio de loteamentos, sob o caráter da especulação imobiliária. A partir da década de 50 a ocupação por ranchos foi-se intensificando. A opção por terrenos às margens do rio deveu-se também ao fato de serem substancialmente mais baratos do que os da cidade e as famílias poderem sobreviver por meio da pesca e agricultura familiar.

Atualmente existem 137 edificações ou ranchos, localizados às margens do rio Mogi-Guaçu e que surgiram a partir do loteamento de antigas propriedades rurais: antigo sítio São Sebastião (36 ranchos); loteamento Estela(26 ranchos); entre Estela e Barranco Vermelho (9 ranchos); Barranco Vermelho (45 ranchos); entre a ponte nova e ponte velha (21 ranchos). 
Geralmente os ranchos são ocupados pelo caseiro e sua família, ou utilizados como residência pelos proprietários. Os loteamentos parecem verdadeiros conjuntos habitacionais e as edificações são construídas umas próximas às outras, mantendo o mesmo padrão de construção popular e mesmo estilo de muros e calçadas. Em nenhum dos 137 ranchos existe rede de esgoto, iluminação publica (existe iluminação particular), não há rede elétrica. Existe coleta de lixo realizada pela prefeitura municipal.

Desse conjunto, 62 ranchos são considerados regulares, pois estão fora da área de preservação permanente -APP e 75 são considerados irregulares, e em desrespeito às leis urbanas e ambientais, porque foram construídos fora dos padrões exigidos pela legislação ambiental, a Lei n. ${ }^{\circ} 4771$ de 1965, localizados a menos de 100 metros de distância da margem do rio, sendo utilizados como residências.

Do ponto de vista da legislação municipal, somente 39 estão cadastrados no sistema de tributação municipal e regularizados pela prefeitura municipal e recolhem IPTU. O restante, ou seja, 98 ranchos, são considerados irregulares e inexistentes pela administração pública, dado que não há condições de fiscalização.

Emrazão dessa irregularidade, a Promotoriado Meio Ambiente do município de Sertãozinho solicitou a retirada das edificações (ranchos) da margem do rio. Os rancheiros em condições irregulares são considerados pela lei como "criminosos permanentes", ou seja, enquanto essas edificações permanecerem intactas, os rancheiros responderão pelo crime praticado.

Diante desse quadro, no ano de 2004, os rancheiros se mobilizaram e fundaram a Associação "Princesa do Mogi", com a finalidade proporcionar apoio jurídico aos proprietários de ranchos irregulares e regulares e aos que utilizam os ranchos como único domicílio. Além disso, fornecer apoio técnico por parte de órgãos públicos, no intuito de capacitá-los para desenvolverem atividades que proporcionam trabalho e renda.

ATIVIDADES PRODUTIVAS AGRícOLAS E NÃo AGRíCOLAS PRESENTES: CONDIÇÕES DE PRODUÇÃO E DE COMERCIALIZAÇÃo

As atividades produtivas agrícolas e não agrícolas desenvolvidas pelos rancheiros têm como característica comum a produção em pequena escala e o caráter artesanal. As atividades desenvolvidas são as seguintes: criação de peixes em tanques redes, associada ao turismo e pesca para recreação; turismo rural para lazer associado à presença de alojamento e pousada e de um restaurante, onde se desenvolvem festas típicas da região; criação de suínos para processamento e fabricação de embutidos; hortas; criação de carneiros; plantação de milho verde; granjas; e uma diversidade de horticultura.

\begin{tabular}{|c|c|c|c|c|c|c|c|}
\hline Ranchos & $\begin{array}{c}\text { Peixes em } \\
\text { tanques } \\
\text { redes }\end{array}$ & $\begin{array}{c}\text { Agricultur } \\
\text { a }\end{array}$ & Horticultura & Suinocultura & $\begin{array}{c}\text { Galinhas e } \\
\text { frangos }\end{array}$ & $\begin{array}{c}\text { Turismo } \\
\text { rural }\end{array}$ & $\begin{array}{c}\text { Fabricação } \\
\text { de } \\
\text { embutidos }\end{array}$ \\
\hline 1 & & & $\mathrm{X}$ & $\mathrm{X}$ & $\mathrm{X}$ & & $\mathrm{X}$ \\
\hline 2 & & & $\mathrm{X}$ & & & & \\
\hline 3 & $\mathrm{X}$ & & & & & $\mathrm{X}$ & \\
\hline 4 & & & $\mathrm{X}$ & & $\mathrm{X}$ & & \\
\hline 5 & & $\mathrm{X}$ & & & & & \\
\hline 6 & & & $\mathrm{X}$ & & & & \\
\hline 7 & & & $\mathrm{X}$ & $\mathrm{X}$ & $\mathrm{X}$ & & \\
\hline 8 & & $\mathrm{X}$ & $\mathrm{X}$ & & & & \\
\hline 9 & & $\mathrm{X}$ & $\mathrm{X}$ & & & & \\
\hline 10 & & & & & & \\
\hline
\end{tabular}

Quadro 1 -Atividades produtivas praticadas pelos ranchos pesquisados.

Fonte: Pesquisa de campo, 2008. 
Há seis tanques para a criação de peixes, sendo que dois são reservados somente para a criação de tilapias e quatro, para criação de carpas, pacus, tambaquis, matrinchãns, curimbas e cascudos. Os peixes são criados em tanque na Estância Fazendinha, antigo pesque-pague, que está localizada na área de ranchos. Os peixes são consumidos pela própria estância e também vendidos a visitantes. Em média são consumidos e vendidos 80 quilos por semana, num total aproximadamente de 320 quilos por mês. A estância também compra produtos como embutidos, aves e verduras dos ranchos que fazem parte da associação.

Seis estabelecimentos desenvolvem horticultura: plantam alface, quiabo, abóbora, mandioca, berinjela, jiló, brócolis, almeirão, cheiro-verde e mantêm viveiros de mudas. Os ranchos envolvidos são, respectivamente, os ranchos Esperança, Fortaleza, Paraíso dos Santos, Santa Maria, Cesar Valera e sítio Calipal I. No Calipal I existem dois viveiros de mudas, cinco grandes hortas, um tanque de água para irrigação, dez carriolas, um caminhão para o transporte e estão empregados três funcionários. O sítio vende sua produção para o Ceasa de Ribeirão Preto. Os outros ranchos vendem suas produções na feira municipal de Barrinha e também para o sítio Calipal I, que faz a intermediação e vende a produção para o Ceasa de Ribeirão Preto.

A criação de porcos é desenvolvida por dois ranchos: Fortaleza eLopes. Somente o ranchoFortaleza temmelhor estrutura e fabrica embutido. Possui atualmente 26 matrizes, 3 reprodutores e 1 mil leitões. Também possui 1 mil galinhas e uma criação de chester, com aproximadamente 100 aves; a criação de chester vem sendo desenvolvidarecentemente. A maior parte da carne derivada da criação de suínos é transformada em embutidos pelos próprios proprietários, por meio de uma pequena indústria caseira, onde são fabricados linguiças e chouriço. A produção é vendida na feira municipal de Barrinha, para alguns restaurantes e direto ao consumidor; emmédia, os proprietários vendem 50 quilos de embutidos por semana, chegando, em semanas atípicas, a vender 70 quilos de embutidos e 50 aves abatidas. As criações de porcos e aves têm alvará do município e autorização do Departamento de Preservação dos Recursos Naturais
- DPRN do município de Ribeirão Preto.

Em visita à edificação, foi possível confirmar os cuidados dos proprietários em relação às vacinas e higienização do local; também foram constatadas dificuldades em manter a atividade em decorrência de falta de mercados e de incentivos do poder público local, que poderia comprar parte da produção para a merenda escolar.

Três ranchos praticam a pequena agricultura familiar. As plantações são de milho verde, quiabo, jiló e berinjela. Os ranchos são: Fundo, Cesar Valera e Santa Maria. A produção é vendida na feira municipal de Barrinha e também para o sítio Calipal I. Três ranchos criam galinhas e frangos: o Fortaleza, Vicente e Lopes. A produção é vendida na feira municipale para a Estância Fazendinha.

A comercialização dos produtos locais é realizada na feira municipal de Barrinha. A feira é realizada aos domingos e estende-se por três quarteirões e meio, num total aproximadamente de 350 metros. Há aproximadamente cem barracas que vendem aves vivas e abatidas, milho e seus derivados, embutidos como linguiça e chouriço, legumes, verduras, doces caseiros, mandioca, vassouras e frutas diversas, principalmente.

Os feirantes são rancheiros do município, e ainda sitiantes e assentados oriundos de assentamentos rurais dos municípios de Jaboticabal, Ribeirão Preto, Pradópolis e Guariba. Há um pequeno pagamento trimestralmente para a Prefeitura do Município de Barrinha. A feira tem início às 6 horas da manhã e vai até aproximadamente as 13 horas, e a população da região e municípios vizinhos recorre à feira de Barrinha para encontrar produtos mais artesanais e difíceis de serem encontrados, como galinhas caipiras, patos, gansos e vassouras plantadas e amarradas pelos produtores. Afeira existe há 20 anose é frequentada pela população do município e região e a prática de comprar esses produtos na feira faz comque o município não possua outros varejões.

A feira de Barrinhaé a única fonte de renda da maioria dos feirantes; portanto, sustenta aproximadamente cem famílias de vários municípios, que representam vários segmentos de baixa renda, como assentados, rancheiros, chacareiros e outros. O quadro abaixo resume as condições de comercialização. 


\begin{tabular}{|c|c|c|c|}
\hline Rancho & A tividade & Mercado Consumidor & $\begin{array}{c}\text { Produção mensal } \\
\text { (média) }\end{array}$ \\
\hline Ranch o Fortaleza & $\begin{array}{c}\text { Criação de porcos e } \\
\text { fabric ação de embutidos }\end{array}$ & $\begin{array}{c}\text { Feira Municipal de } \\
\text { Barrinha, restaurantes e } \\
\text { terceiros }\end{array}$ & 200 quilos \\
\hline Rancho Fortaleza & $\begin{array}{l}\text { Criação de galinhas e } \\
\text { chesters }\end{array}$ & $\begin{array}{c}\text { Feira Municipal de } \\
\text { Barrinha, restaurantes e } \\
\text { terceiros }\end{array}$ & 200 aves \\
\hline Sítio Calipal I & $\begin{array}{l}\text { Plan tação de hortaliças: } \\
\text { alface, almeirão, couve e } \\
\text { rúcula }\end{array}$ & $\begin{array}{l}\text { CEASA de Ribeirão } \\
\text { Preto }\end{array}$ & 720 caixas \\
\hline Estância Fazendinha & $\begin{array}{c}\text { Criação de tilápias, } \\
\text { carpas, pacus, tambaquis, } \\
\text { matrinchãns, curimbas e } \\
\text { cascudos }\end{array}$ & $\begin{array}{l}\text { Visitan tes da região e o } \\
\text { seu próprio restaurante }\end{array}$ & 320 quilos \\
\hline Estância Fazendinha & Restaurante & Turistas & 1.600 refeições \\
\hline Ranch o do Vicen te & $\begin{array}{c}\text { Plantação de hortaliças e } \\
\text { legumes }\end{array}$ & $\begin{array}{c}\text { Sítio Calipal I que } \\
\text { intermedia a ven da para } \\
\text { o CEASA }\end{array}$ & 20 caixas \\
\hline Rancho Fundo & Plan tação de milho verde & $\begin{array}{c}\text { Feira Municipal de } \\
\text { Barrinha }\end{array}$ & 80 caixas \\
\hline Ranch o Esperan ça & $\begin{array}{c}\text { Plan tação de quiabo e } \\
\text { abóbora }\end{array}$ & $\begin{array}{c}\text { Feira Municipal de } \\
\text { Barrinha }\end{array}$ & 20 caixas \\
\hline Ran cho Lopes & Criação de galinhas & $\begin{array}{c}\text { Feira Municipal de } \\
\text { Barrinha }\end{array}$ & 40 aves abatidas \\
\hline Rancho Santa Maria & $\begin{array}{c}\text { Plan tação de berinjela e } \\
\text { jiló }\end{array}$ & $\begin{array}{c}\text { Sítio Calipal I que } \\
\text { intermedia a ven da para } \\
\text { o CEASA }\end{array}$ & 80 caixas \\
\hline Rancho Cesar Valera & Plantação de quiabo & $\begin{array}{c}\text { Sítio Calipal I que } \\
\text { intermédia a ven da para } \\
\text { o CEASA e freira } \\
\text { Municipal deBarrinha }\end{array}$ & 80 caixas \\
\hline $\begin{array}{c}\text { Rancho Paraíso dos } \\
\text { Santos }\end{array}$ & Plantação de mandioca & $\begin{array}{c}\text { Feira Municipal de } \\
\text { Barrinha e moradores } \\
\text { do município }\end{array}$ & 120 caixas \\
\hline
\end{tabular}

Quadro 2 - Atividades produtivas, mercado consumidor e produção por unidade.

Fonte: Pesquisa de campo, 2008.

O turismo ruralé outra atividade importante que se desenvolve na Estância Fazendinha. Iniciou-se em 1984 por uma família do Rio Grande do Sul. Aárea possui 12 hectares e está em processo de recuperação ambiental. Antes de se transformar em estância, a área foi local de extração de argila das margens do rio Mogi-Guaçu. Tendo sido muito degradada pela extração para a produção de cerâmica, formou seis imensas crateras de aproximadamente milmetros quadrados. O localvem sendo recuperado pela família que adquiriu o local e as crateras passarama servir de tanques para criação de peixes, dando início ao pesque-pague do município. A partir de 2000 deixou de ser pesque-pague e transformou-se em estância para explorar o turismo rural.

Desde o ano de 2003 a Estância faz parte da Associação de Turismo Rural da Região de Ribeirão Preto - Aturp, associação que fornece assessoria tambéma 13 outras fazendas de turismo rural da região. 
Atualmente a estância é muito conhecida na região de Ribeirão Preto pelas atrações relacionadas ao turismo rural, como área de camping, prainha, tirolesa, área de pesca, animais para passeios e um centro de educação ambiental, espaço onde são realizadas as reuniões da associação. Também oferece dez bangalôs (apartamentos para hóspedes), cujas construções das edificações foram realizadas entre 2000 e 2006. Dispõe de um restaurante, que oferece refeição diária, recebendo, em média, aos domingos e feriados, aproximadamente 400 pessoas. Há umlago artificial para passeio, trilha ecológica às margens do rio Mogi-Guaçu, com aulas de educação ambiental e também práticas de ecoturismo para alunos de escolas públicas e particulares de toda a região. Emprega cerca de 20 funcionários, entre cozinheiras, garçons, monitores, professores, jardineiros, porteiros, camareiras, faxineiras, contadores e trabalhadores braçais.

\section{Formação da Associação Princesa do Mogi:} PARTICIPAÇÃO E DECISÕES

A associação a Associação "Princesa do Mogi", criada em 2004, teve de início a finalidade principal de promover a integração e proteção jurídica aos rancheiros, chacareiros, sitiantes com propriedades regulares. Aproteção ao meio ambiente foi um segundo objetivo claro da associação. No decorrer do tempo, a associação começou a proporcionar apoio jurídico aos proprietários de ranchos irregulares. A associação promoveu encontros entre advogados e rancheiros no intuito de informá-los sobre a verdadeira situação legal e os corretos procedimentos a serem tomados.

A partir de 2005, a associação extrapolou o seu papel de apoio jurídico e está buscando articular, junto a instituições parceiras, atividade de capacitação aos rancheiros para que os mesmos possam desenvolver atividades que proporcionem trabalho e renda. Ainda em 2005 obteve o apoio do Serviço de Apoio às Micro e Pequenas Empresas - Sebrae e do Serviço Nacional de Aprendizagem Industrial-Senai para a criação de peixes em tanques redes, horticultura e criação de aves, assim como assessoria do Departamento de Piscicultura da Universidade Estadual Paulista - Unesp de Jaboticabal.
A maioria dos rancheiros acredita que houve progresso em relação às atividades desenvolvidas nos últimos dois anos, e deposita em parte esse progresso à fundação e atuação da associação, que vem cumprindo com seu papel de motivadora e articuladora das relações sociais entre os envolvidos, também promovendo reuniões, palestras, cursos e excursões a outras localidades que praticam a pluriatividade no campo, como, por exemplo, excursão a Ilha Solteira, onde existem grupos que praticam a criação de peixes em tanques redes.

É por meio da associação que os rancheiros analisam e tomam as decisões sobre todas as questões que abrangem a área de ranchos, como problemas nas vias vicinais, falta de fossas sépticas nas edificações, problemas relacionados à venda e escoamento dos produtos, dificuldades em relação ao mercado consumidor, principalmente. Os associados reúnemse periodicamente na Estância Fazendinha, onde atualmente é a sede da associação, e discutem também questões da esfera política, pois acreditam que o desenvolvimento de suas respectivas atividades econômicas e o desenvolvimento daquela localidade rural passam pelo respaldo de políticas públicas.

\section{REDE DE COOPERAÇÃO E A ARTICULAÇÃo DOS ATORES LOCAIS}

Um dos aspectos mais relevantes promovido pela foi a formação de uma rede informal de relações de cooperação, fundamental para a consolidação do grupo. Essa rede de cooperação tem realizado papel relevante para a produção, comercialização e venda da produção e para a continuidade e fortalecimento das relações sociais entre as pessoas do local. Participam dessa rede, além dos ranchos e da associação mencionada, a Prefeitura Municipal de Barrinha, o Ceasa de Ribeirão Preto e os moradores do município. Na formação e atuação da rede, a participação da prefeitura tem sido bastante irregular.

A rede de cooperação revela-se na etapa de produção de alimentos, por exemplo, quando, no momento do plantio, partilham o mesmo trator, ou mesmo quando se ajudam mutuamente, no momento 
da colheita. Todavia, a decisão sobre o que produzir é individual. Cada produtor produz isoladamente dentro de sua respectiva área ou unidade e, juntamente com sua família e funcionários, opta pela cultura com que mais se identifica. Não há critérios preestabelecidos em grupo para decidirem qual cultura é mais apropriada para cada área, em decorrência do solo, relevo e quantidade de água disponível. Mas há trocas de experiências de cada um nos momentos em que os rancheiros se reúnem na associação.

A rede de cooperação, por meio da associação, atua fortemente na etapa da venda e comercialização dos produtos. O sítio Calipal I faz a intermediação da venda dos produtos de muitos rancheiros para o Ceasa de Ribeirão Preto, a Estância Fazendinha também compra os produtos de muitos rancheiros e a Prefeitura Municipal de Barrinha promove a feira municipal.

Portanto, em razão da reciprocidade observada entre eles, vem sendo construída uma teia de relações entre esses atores, constatando a presença de uma "rede de cooperação", embora informal.

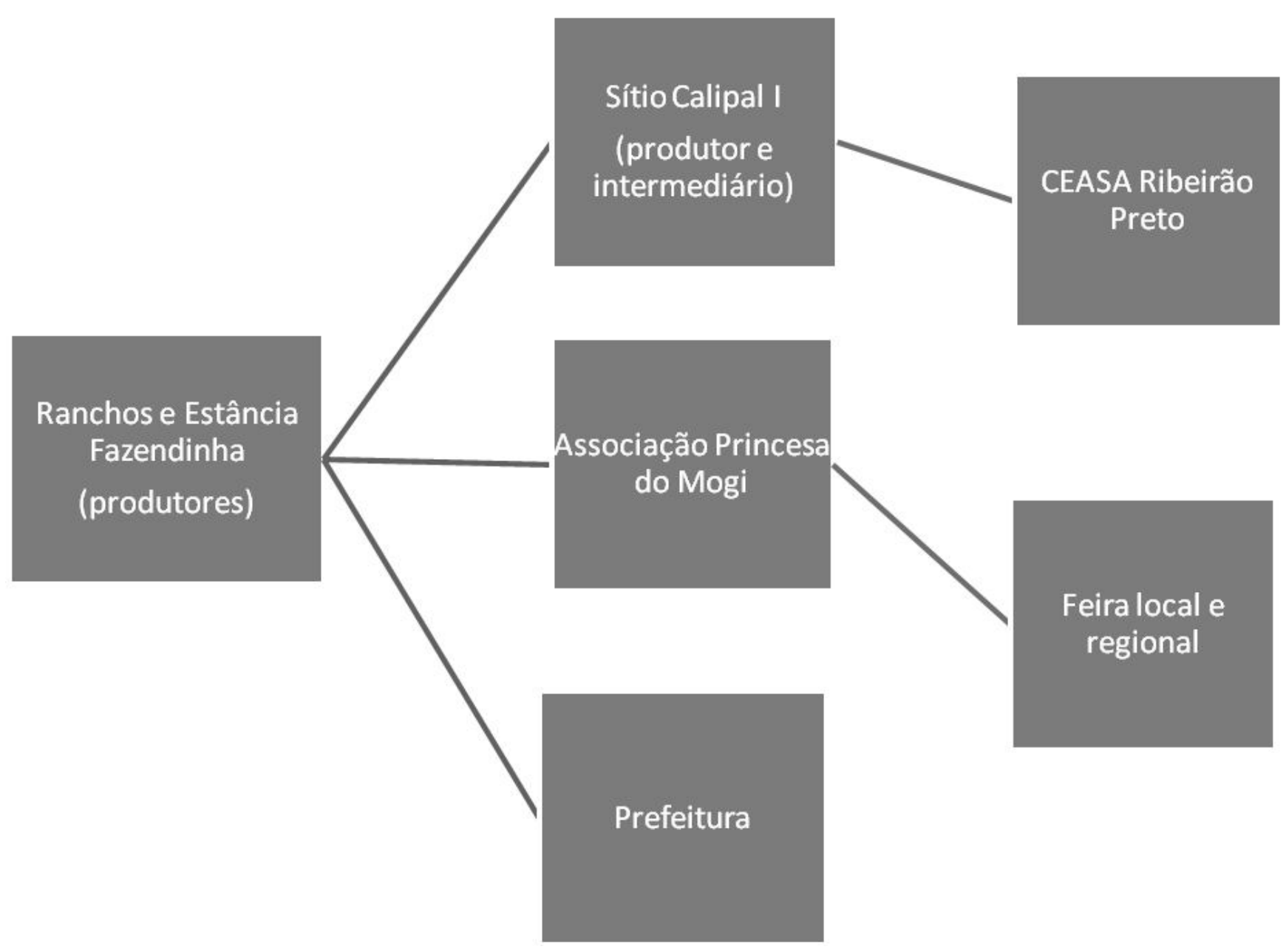

Figura 1 - Desenho da rede de cooperação.

Fonte: Pesquisa de campo, 2008. 
Alguns atores dentro da "rede de cooperação" têm papel mais relevante, como o sítio Calipal I, a Estância Fazendinha, a Prefeitura do Município de Barrinha e o Ceasa de Ribeirão Preto, mas, quando se analisa a rede como um todo, se percebe que todos os participantes cumprem com seus papéis para o fortalecimento das atividades econômicas.

Analisando o papel da cada ator social nessa experiência, pôde-se observar o grau de influência ou importância de cada um. O sítio Calipal I faz a intermediação da venda dos produtos de muitos rancheiros ao Ceasa de Ribeirão Preto, pois esses rancheiros não plantam em grande quantidade - seria muito difícil a venda particular para o Ceasa. Mas, ao repassarem seus produtos ao sítio Calipal I, a renda da venda dos produtos torna-se mais segura para todos. Portanto, os rancheiros não se relacionam diretamente com o Ceasa; esse papel de relacionamento é tarefa do sítio Calipal I.

Observaram-se também outras formas de cooperação nos momentos de lazer, quando festejam conjuntamente datas simbólicas, ou em momentos de dificuldades com a saúde, quando alguém precisa de ajuda. Pode-se, assim, confirmar que os laços entre os atores têm sido acompanhados de relações interpessoais com uma dimensão emocional. Isso porque, nessa fase, ocorreu um tipo de confiança que é desenvolvida ao longo de reputação nos relacionamentos, em que a confiança é criada e incrementada mais em nível interpessoal.

A presença da prefeitura na realização das atividades do grupo é bastante irregular, embora seja parcialmente responsável pela realização da feira semanal, onde são vendidos os produtos. A prefeitura também colaborou no início da atividade de criação de peixes em tanques, mas não acompanha mais o desenvolvimento dessa atividade. Já em relação às outras atividades praticadas, há ausência dos órgãos públicos no que tange à orientação profissional nas áreas agrícola, horticultura e pecuária.

Os rancheiros, há tempos, solicitam da prefeitura municipal uma atenção maior àquela área, pois as estradas vicinais que viabilizam os fluxos das produções encontram-se inacessíveis e abandonadas pelo poder público. Não há asfalto nem galerias pluviais nas estradas, fazendo com que, em dias de chuva, as estradas fiquem interditadas.

Em relação à Estância Fazendinha, que é considerada o centro de apoio, por ser a sede da Associação Princesa do Mogi, as solicitações feitas para o poder público são ainda maiores, como o asfaltamento da principal estrada vicinal, pois a estância depende dela para receber os turistas, e a retirada de entulhos e resíduos de construções civis que são depositados na referida estrada, inviabilizando o tráfego de carros e ônibus.

A estância também cobra da Prefeitura Municipal de Barrinha, desde 2001, o tratamento do esgoto residencial que é lançado "in natura" no rio MogiGuaçu, poluindo suas águas, que são a maior atração dos turistas. Portanto, a participação da esfera pública municipal na viabilização dessas atividades é considerada pelo grupo como ineficiente.

Conclui-se, portanto, que esses rancheiros estão articulados por meio de importante "rede de cooperação" informal que atua em vários segmentos, mas que tem ação fundamental ao criar condições para comercializar e vender sua produção. Porém, os atores locais envolvidos, desde os rancheiros até o mercado consumidor final, não têm consciência clara de sua articulação, mas não podem prescindir dela. Compreendem que esse arranjo criativo desenvolvido por eles, de uma maneira singular, foi a forma que encontraram para evitarem o desemprego e a exclusão social, inclusive a exclusão territorial, pois essa articulação promove e assegura suas permanências nas suas respectivas unidades rurais.

\section{Origem Social doS RANCHEIROS E ELEMENTOS DE "RURALIDADE" PRESENTES NO COTIDIANO DA VIDA DOS RANCHEIROS}

A maioria dos rancheiros é proveniente da cidade de Barrinha, para onde vieram com a finalidade de trabalhar nas lavouras de cana-de-açúcar. Com a perda do emprego na agricultura, passaram a viver de pequeno comércio ou de serviços urbanos. A fixação dessa população em ranchos nos loteamentos 
estudados, como se viu, ocorreu em razão dos altos preços dos aluguéis na área urbana.

Apesar de a comunidade estudada ser considerada periurbana, em decorrência da expansão do perímetro urbano do município, a população, na sua maioria, tem mostrado interesse em preservar elementos de ruralidade, tal como defendida por Moreira (2005).

A pesquisa constatou elementos de "ruralidade" e que a comunidade, apesar da presença de aspectos muito modernos e até próprios da sociedade global, não perdeu sua identidade em relação ao mundo rural. Existem antenas de televisões e parabólicas sobre os telhados dos ranchos, energia elétrica no lugar dos antigos lampiões e lamparinas, carros e camionetes nos lugares das carroças e carros-de-boi. Também a comunidade procura preservar e festejar datas simbólicas, como as festas juninas, resgatar danças típicas do meio rural, como a "catira", e preservar as modas de viola e música ritmada pela sanfona. É importante enfatizar que essa identidade rural não é forçada, mas espontânea.

\begin{tabular}{|c|c|c|c|c|c|c|}
\hline $\begin{array}{c}\text { Relação } \\
\text { dos } \\
\text { ranchos }\end{array}$ & $\begin{array}{l}\text { Cana-de- } \\
\text { açúcar }\end{array}$ & $\begin{array}{c}\text { Outras } \\
\text { ag riculturas }\end{array}$ & $\begin{array}{l}\text { Serviços } \\
\text { Urbanos }\end{array}$ & $\begin{array}{c}\text { Área } \\
\text { urbana de } \\
\text { Barrinha }\end{array}$ & $\begin{array}{c}\text { Outro } \\
\text { município }\end{array}$ & $\begin{array}{l}\text { Outro } \\
\text { estado }\end{array}$ \\
\hline 1 & $X$ & & Comércio & $X$ & & \\
\hline 2 & $X$ & $X$ & & $X$ & & \\
\hline 3 & $X$ & $\mathrm{X}$ & & & & $\begin{array}{c}\text { Rio } \\
\text { Grande } \\
\text { do Sul } \\
\end{array}$ \\
\hline 4 & $X$ & & Comércio & $X$ & & \\
\hline 5 & & & Comércio & $X$ & & \\
\hline 6 & $\mathrm{X}$ & & In dústria & & $X$ & \\
\hline 7 & $\mathrm{X}$ & & & & $X$ & \\
\hline 8 & $X$ & & Comércio & $X$ & & \\
\hline 9 & $X$ & $X$ & & $X$ & & \\
\hline 10 & $X$ & & $\begin{array}{l}\text { Prestadora } \\
\text { de Serviço }\end{array}$ & & $X$ & \\
\hline
\end{tabular}

Quadro 3 - Origem dos rancheiros e atividades anteriormente praticadas.

Fonte: Pesquisa de campo, 2009. 
Manter essas tradições não significa "atraso", "nostalgia", como muitos acreditam. Scheider (2003), ao analisar o meio rural, mostra que o mesmo, atualmente, traz consigo uma complexidade de alterações sociais, culturais e identitárias. É comum aos membros dessas comunidades se reunirem ao redor do fogão à lenha e saborear comidas como galinhada, porco no rolete, leitoa assada em forno à lenha, polenta com frango, dentre outros pratos típicos; tudo é motivo para reunir, comer, beber, dançar e festejar. As vivências da comunidade analisada mostram que há uma lógica de sociabilidade básica que não contempla somente questões de ordem econômica ou novas formas de organizações para gerar trabalho e renda, mas também procura resgatar tradições, valores, hábitos e costumes do "antigo" rural.

Essa comunidade consegue conviver com o "novo" sem esquecer-se das tradições do mundo rural. A pesquisa constatou a presença de jovens que estudam em colégios particulares, em municípios próximos a Barrinha ou que cursam faculdades em outras regiões, e que participam de festividades típicas do mundo rural. Talvez a singularidade dessa comunidade esteja em conseguir manter as tradições e ao mesmo tempo conviver com o novo, com as máquinas de apoio a agricultura, comos tratores modernos, com as antenas parabólicas, com o fogão a gás, etc.

\section{EMPREGO, RENDA E MEIO AMBIENTE}

$\mathrm{O}$ estudo mostrou que a renda derivada das atividades econômicas realizadas pela comunidade é a única fonte para a sobrevivência do grupo. A maioria dos entrevistados está satisfeita com a renda, pois é suficiente para suprir as necessidades da família, evita que membros da família migrem para a cidade à procura de emprego, ou seja, o grupo consegue permanecer unido em sua propriedade, viver da atividade realizada e gerar trabalho para outras pessoas.

O quadro abaixo apresenta a geração de emprego no universo da pesquisa. O sítio Calipal I, além de viver somente da renda da atividade, gera emprego para três funcionários, ou seja, a atividade gera trabalho e renda para outras pessoas que não fazem parte da família.

\begin{tabular}{|c|c|c|c|c|c|c|c|c|c|}
\hline \multirow[t]{2}{*}{ Ranchos } & \multicolumn{4}{|c|}{ Membros da Família } & \multicolumn{4}{|c|}{ Empregados } & \multirow[t]{2}{*}{ Total } \\
\hline & 1 & 2 & 3 & +3 & 1 & 2 & 3 & +3 & \\
\hline 1 & & & $\mathrm{X}$ & & & & & & 3 \\
\hline 2 & & $\mathrm{X}$ & & & & & $\mathrm{X}$ & & 5 \\
\hline 3 & & & & 4 & & & & 20 & 24 \\
\hline 4 & & & $\mathrm{X}$ & & & & & & 3 \\
\hline 5 & & $\mathrm{X}$ & & & & X & & & 4 \\
\hline 6 & & $\mathrm{X}$ & & & & & & & 2 \\
\hline 7 & & & & 4 & & & & & 4 \\
\hline 8 & & $\mathrm{X}$ & & & & & $X$ & & 5 \\
\hline 9 & & & $\mathrm{X}$ & & X & & & & 4 \\
\hline 10 & & $\mathrm{X}$ & & & & $\mathrm{X}$ & & & 4 \\
\hline Total & & & & & & & & & 58 \\
\hline
\end{tabular}

Quadro 4 - Geração de emprego.

Fonte: Pesquisa de campo, 2009. 
No caso da Estância Fazendinha, as atividades realizadas geram renda para toda a família e seus agregados, e contribui na geração de trabalho e renda para 20 funcionários que trabalham na estância e moram no município de Barrinha. A estância acredita que, se houvesse estímulos por parte da esfera pública municipal, atualmente estaria empregando 50 por cento a mais do que emprega. Já o rancho Fortaleza, que trabalha com embutidos, programa dobrar a sua produção, pois realizou um grande investimento para adequar toda a área na atividade de suinocultura, esperando que o investimento lhe proporcione mais retorno, como já vem ocorrendo.

Quando se trata das questões ambientais, a pesquisa concluiu que houve um grande avanço em relação ao cumprimento da legislação ambiental. Desde 2002 os rancheiros vêm construindo fossas sépticas em suas edificações, primeiramente porque houve um grande receio de serem multados pela Promotoria do Meio Ambiente do município de Sertãozinho, a que o município de Barrinha está integrado. A pesquisa também apurou razoável nível de educação ambiental em razão da atuação da associação com palestras e cursos. Já estiveram presentes na Associação Princesa do Mogi, realizando palestras relacionadas ao meio ambiente, biólogos, zootecnistas, professores da Unesp de Jaboticabal e o presidente da Associação de Rancheiros do Rio Pardo.

A preocupação com os problemas ambientais por parte dos rancheiros envolve a recuperação da mata ciliar das suas propriedades e a luta para que a prefeitura municipal trate seu esgoto doméstico. A associação vem solicitando para a Prefeitura de Barrinha, desde 2001, o tratamento do esgoto residencial que é lançado "in natura" no rio MogiGuaçu, poluindo suas águas, que são a maior atração dos turistas. Portanto, a participação da esfera pública municipal na viabilização dessas atividades é considerada pelo grupo como ineficiente.

\section{CONSIDERaÇões Finais}

Os estudos sobre o "novo rural brasileiro" têm mostrado experiências relevantes que grupos, indivíduos e comunidades rurais vêm praticando para gerarem trabalho e renda e permanecerem no campo. A pesquisa realizada confirma essa assertiva, indicando que a comunidade estudada vive uma nova forma de ocupação da força de trabalho no meio rural e que está voltada para uma diversidade de atividades agrícolas e não agrícolas.

Concluiu-se que a diversidade de atividades praticadas não significa que as famílias domiciliadas nesse espaço rural estejam abandonando as atividades agrícolas; pelo contrário, pode-se observar a presença de pluriatividade no campo em razão da interação entre as decisões individuais e coletivas como contexto social e econômico em que estas estão inseridas. Não se pode caracterizar a experiência como atrasada ou nostálgica, pois o estudo revelou grande integração entre os moradores, para os quais a preservação das tradições locais se configura em fator de sucessivos encontros e de confraternização.

O estudo também revelou as dificuldades que essa comunidade encontra no seu cotidiano para desenvolver essas atividades, pois a falta de infraestrutura, como estradas, energia elétrica e serviços de água e esgotos, dificulta o progresso e o desenvolvimento local/rural; isso não significa que essa comunidade não tenha melhorado sua qualidade de vida; pelo contrário, houve avanços e progresso significativos em decorrência da união dos grupos envolvidos. Portanto, esses avanços se devem ao fato de essa comunidade ter se articulado por meio de uma rede de colaboração e solidariedade, cujo elo se deu por meio da criação da Associação Princesa do Mogi.

O estudo dessa experiência também vem reforçar a importância da presença de redes de cooperação, em confronto com as dificuldades encontradas quando as famílias trabalham isoladamente. O estudo identificou que a possível formação de uma cooperativa aumentaria de forma substancial emprego e renda nessa área rural.

Pode-se dizer que a comunidade estudada encontrou uma forma para driblar o desemprego e a 
crise econômica sempre presentes em sua permanência no mundo rural. Também ficou claro que essa comunidade somente permanecerá enquanto comunidade rural se obtiver maior apoio de políticas públicas, capacitação profissional por meio de órgãos públicos e apoio jurídico para legalizar suas propriedades.

Destaca-se que a diversidade de atividades econômicas desenvolvidas encontrou ambiente favorável nessa área e vem crescendo de forma substancial por meio de atividades econômicas, como criação de peixes em tanques, fabricação de embutidos, turismo rural, horticultura, viveiros de mudas, suinocultura, principalmente. Contudo, não pode ser caracterizada como tipicamente pluriativa, pois também há a presença de atividades tradicionais, como arrendamentos de terras para a indústria canavieira, agricultura perene e permanente, como roças de algodão e amendoim.

Os laços sociais fortes e a densidade da redes social informal que se desenvolveu criou um ambiente favorável à cooperação, responsável por reduzir os custos de operação das transação. Porém, redução de custos não foi o único motivo para a formação da rede de relacionamentos, pois envolveu a criação de valores, como o desenvolvimento de conhecimentos em conjunto e outras consequências sociais e afetivas que transcendem a simples vontade de reduzir custos de transação. A questão da "confiança" entre os atores envolvidos foi primordial para que os objetivos fossem alcançados. A confiança observada nas relações entre os rancheiros vem da consciência da impossibilidade de sobreviverem se não houver uma ação conjunta. Assim, pode-se afirmar para o caso analisado que a confiança tem sido vista, além de um resultado e de um meio da interação cooperativa, como um aspecto do contexto organizacional e um antecedente da cooperação.

Concluiu-se, assim, que a permanência dessa comunidade se deveu, acima de tudo, aos arranjos criativos e inovadores que essa comunidade encontrou no percurso de sua própria história.

\section{REFERÊNCIAS}

ABRAMOVAY, R. O capital dos territórios: repensando o desenvolvimento rural. Economia Aplicada, v. 14, n. 2, p. 379-397, abr-jun, 2000.

CAMPANHOLA, C.; SILVA, G. J. Diretrizes de Políticas Públicas Para o Novo Rural Brasileiro: incorporando a noção de desenvolvimento local. In: CONGRESSO BRASILEIRO DE ECONOMIA E SOCIOLOGIA RURAL, Anais... Foz do Iguaçu: SOBER, 1999. p 47-57.

CORRÊA, J. M; CORRÊA, W. K.; GERARDI, L. H. O. In: a problemática da definição e da delimitação do espaço rural e urbano. Geografia, Rio Claro, v. 26, n. 1, p. 37-49, 2001.

COSTA, L. (Org.). Uma introdução às dinâmicas da conectividade e da auto-organização. Brasília/ DF, 2003. Disponível em: 〈http://www.wwf.org〉. Acesso em: 22 mar. 2008.

GOMÉZ, E. S. Nueva ruralidad? Um aporte al debate. Estudos Sociedade e Agricultura. Rio de Janeiro: UFRJ/CPDA, n. 17, p. 5-32, 2001.

INSTITUTO BRASILEIRO DE GEOGRAFIA E ESTATÍSTICA - IBGE. Município de Barrinha. Disponível em: <http://www.ibge.gov.br-IBGEcidades $>$. Acesso em: 2007.

JERÔNIMO, F. B. A confiança em redes: a experiência de uma rede por sete cooperativas do setor agroalimentar no Rio Grande do Sul. 2005. 173f. Dissertação de (Mestrado) - Universidade Federal do Rio Grande do Sul, Porto Alegre, 2005.

KAGEYAMA, A. A. Desenvolvimento rural: conceitos e aplicação ao caso brasileiro. Porto Alegre: UFRGS, 2008.

RODRIGUES, A. M. Produção e consumo do e 
no espaço: problemática ambiental urbana. 2. ed. São Paulo: Hucitec, 1997.

SÃO PAULO (Estado). Secretaria do Meio Ambiente. Macrozoneamento das bacias dos Rios Mogi-Guaçu, Pardo e Médio Grande. São Paulo: 1995.

SCHNEIDER, S. A pluriatividade na agricultura familiar. Porto Alegre: UFRGS, 2003.

. Agricultura familiar e industrialização:

pluriatividade e descentralização industrial no Rio Grande do Sul. Porto Alegre: UFRGS, 1999.

- Aagricultura familiar em uma época de transformações: a pluriatividade como estratégia familiar de reprodução social. In: WORLD CONGRESS OF RURAL SOCIOLOGY, 10, IRSA: Rio de Janeiro, Brasil, 2000.

. Tendências e temas dos estudos sobre desenvolvimento rural no Brasil. In: CONGRESS OF THE EUROPEAN SOCIETY FOR RURAL SOCIOLOGY, 22 Wageningen, Holanda, 2007.

SHIKI, S.; SILVA, J. G.; ORTEGA, A. C. Agricultura, meio ambiente e sustentabilidade do cerrado brasileiro. Campinas: Embrapa/ Unicamp, 1997.
. A nova dinâmica da agricultura

brasileira. Campinas: Unicamp, 1998.

SILVA, J. G. Velhos e Novos Mitos do Rural Brasileiro. 1999. Disponível em: <http:// www.eco.unicamp.br/projetos/rurbano.htm>. Acesso em: 20 jan. 2006.

SILVA, M. A. M. Trabalho e trabalhadores na região do "mar de cana e do Rio de álcool". Disponível em: <http:// www.jori.ribeiraopreto.sp.gov.br/cerest/publicaçoes/ mar-cana.pdf>. Acesso em: 9 jul. 2008.

VEIGA, J. E. A face rural do desenvolvimento natureza, território e agricultura. Porto Alegre: UFRGS, 2000.

. O Brasil rural ainda não encontrou seu eixo de desenvolvimento. Estudos Avançados, v. 15, n. 43, p. 101-119, 2001.

Desenvolvimento sustentável: o desafio do século XXI. Rio de Janeiro: Garamond, 2005.

WANDERLEY, M. N. B. A emergência de uma nova ruralidade nas sociedades modernas avançadas - o "rural" como espaço singular e ator coletivo. Estudos Sociedade e Agricultura, n. 15, p. 87145, 2000.

RECEBIDO EM 27/10/2010

ACEITO EM 21/11/2010 